\title{
Impact of Cataract Surgery on Quality of Life in Plateau State, Nigeria
}

\author{
OP Odugbo, MBBS, MCEH, FWACS, FMCOphth, OE Babalola MBBS,FWACS, FMCOphth, RE Morgan \\ MBBch, FWACS, FMCOphth \\ Department of Ophthalmology, Jos University Teaching Hospital, Jos
}

\section{SUMMARY}

Aim: To evaluate the outcome of cataract surgery subjectively by assessing functional vision in terms of quality of life(QOL), activities of daily living ( $A D L)$, and patient's satisfaction.

Methodology: This was an observational and multicentered study in which patients with age-related cataract who had surgery in Plateau State from $1^{\text {st }}$ October $2002-31^{\text {st }}$ March 2003 constituted the population. The study instrument was the standardized Visual Function (VF-14) and Quality of Life (QOL) questionnaires developed by the Cataract Patient Outcome Research Team (PORT), and designed to measure the impact of impaired vision on patient's ability to perform daily activities. Patient's satisfaction was assessed in relation to the hospital environment, friendliness of staff, nature of surgery and visual restoration.

Result: Two hundred patients were recruited. One hundred and ninety-nine (59.5\%) of them were male and $81(40.5 \%)$ were female. About $34.5 \%$ of the study population were farmers, 97 $(48.5 \%)$ of them were blind and $183(83.6 \%)$ eyes were blind preoperatively. The mean preoperative visual function (VF) and quality of life (QOL) scores of the ninety-seven blind patients were 15.2 (SD 3.9) and 22.4 (SD 4.5) respectively. There was a positive correlation between visual acuity (VA) and subjective visual function $(r=0.92)$, and between $V A$ and QOL $(r=0.83)$. Functional vision improved after cataract surgery; it was more remarkable among blind patients with mean VF and QOL scores of 58.3 and 60.5 respectively. One hundred and twenty-one $(80.1 \%)$ patients expressed satisfaction with the outcome of surgery.

Conclusion: Visual impairment from cataract has a wide implication on health and the quality of life of patients. Cataract surgery in our environment leads to an increase in the quality of life for many cataract-blind patients.

Key words: cataract, blindness, outcome, Plateau State

\section{INTRODUCTION}

Up to $75 \%$ of blindness worldwide is a result of five preventable and treatable conditions. ${ }^{1}$ Cataract, an avoidable cause of blindness, is the leading cause of blindness and low vision worldwide. It accounts for 17.7 million of the 37 million blind persons globally. ${ }^{1}$ Ageing is the commonest cause of cataract. Vision and its impact on daily living apparently go far beyond what could be measured in the clinic using the Snellen chart. ${ }^{2}$ Studies have shown that increased severity of visual impairment is associated with worsening self-rated quality of life scores. ${ }^{3-7}$

It needs to be stressed that the objective of performing cataract surgery is not merely to restore visual function at the 'organ level'. ${ }^{8}$ More importantly, it is intended to restore function and independence at the 'personal level' ${ }^{8}$ In other words, the goal is to achieve restoration of visual function, as measured by visual acuity, contrast sensitivity and other parameters on the one hand, and functional vision, as judged by such measures as activities of daily living (ADL), and patient's satisfaction on the other hand. ${ }^{8}$

Cataract outcome is the result of surgical intervention for visual impairment or blindness due to cataract. ' $F u n c t i o n a l$ outcome' refers to what the patient does now that he/she could not do before, and 'psychological outcome' refers to how much benefit the patient feels (patient satisfaction). ${ }^{10}$

There has been increasing recognition of the importance of assessing patients' views regarding the impact of medical conditions and interventions. This led to the development of standardized Visual Function (VF-14) and Quality of Life (QOL) questionnaires to measure the impact of impaired vision on a patient's ability to perform daily activities by the Cataract Patient Outcome Research Team (PORT). ${ }^{11}$

These instruments are becoming more commonly used as researchers and managers conclude that clinical measures do not fully assess the impact and cost effectiveness of rehabilitation, treatment and surgery. ${ }^{12}$

${ }^{*}$ Correspondence: OP Odugbo, Department of Ophthalmology, Faculty of Medical Sciences, Jos University Teaching Hospital, PMB 2084, Jos, Nigeria • E-mail: odugp@yahoo.com 
Cataract surgery is one of the most cost-effective health interventions which lead to a dramatic increase in quality of life and productivity for many patients. ${ }^{13}$ It is important that resources allocated to medical care is not wasted, especially in countries with severe resource constraints. Unsatisfactory outcomes, when they occur, constitute waste. This is particularly true with regard to cataract surgery. Even the most cursory cost-effectiveness analysis should show that any additional cost associated with producing equipment, surgeon training or expanded patient follow-up is easily justified.

\section{Aim}

To evaluate the outcome of cataract surgery subjectively by assessing functional vision in terms of quality of life(QOL), activities of daily living (ADL), and patient's satisfaction.

\section{METHODOLOGY}

This was an observational, multi-centre, prospective study in which patients with age-related cataract that had cataract extraction within a six-month period $\left(1^{\text {st }}\right.$ October $2002-31^{\text {st }}$ March 2003) constituted the study population.

Approval for conduct of the study was obtained from the Medical Ethics Committee of the Jos University Teaching Hospital. Informed consent was obtained from the medical directors of all the study sites and each patient.

The stratified random sampling technique was used. Cataract surgical centres in the state were divided into four groups as follows: Tertiary health centre (1), state government-owned secondary centre (2), missionary owned secondary centre (3), private hospitals (4). One centre was selected from each of the four groups by balloting. These included Jos University Teaching Hospital (JUTH), Plateau State Specialist Hospital (PSSH), COCIN (Church of Christ in Nigeria) Hospital, Mangu and Na-Allah Na-Kowa Hospital, Barkin-Ladi. Based on the prevalence rate of cataract blindness of $0.5 \%$ (for the entire population) ${ }^{14}$, Plateau State population of 2.78 million, with $15.3 \%$ of the population aged $\geq 40$ years, $\pm 10 \%$ precision and $95 \%$ confidence limit, the minimum sample size was 192 .

Based on the volume of cataract surgery performed in each centre, the patients were recruited as follows: 100 patients from JUTH; 80 from COCIN Hospital, Mangu; 10 from PSSH, and 10 from Na-Allah Na-Kowa Hospital. Consecutive cases (case series) were recruited. The study instrument was a standardized pre-tested structured questionnaire. Research assistants were trained and interobserver error was assessed and standardized.

A 'case' represents a patient aged $\geq 40$ years with agerelated cataract, who has no co-existing ocular morbidity.
Demographic data and preoperative visual acuity (VA) were documented. Subjective visual function (VF) and quality of life (QOL) were assessed preoperatively. Six weeks after surgery, VA was re-assessed and the presenting VA and bestcorrected VA were the criteria used for classifying the physiological (visual) outcome as good $(\geq 6 / 18)$, borderline $(<6 / 18-6 / 60)$ or poor $(<6 / 60)$, based on WHO guidelines. ${ }^{14}$

The subjective VF was assessed using the VF- $14 .{ }^{16}$ It is based on four subscales and contains 14 items that include a spectrum of vision-dependent activities performed in everyday life, that may be affected by cataract. These include visual perception subscale (includes near, intermediate and distant vision limitation), sensory adaptation subscale (includes light/dark adaptation, colour discrimination and glare disability), a single question peripheral vision subscale and a single question depth perception subscale.

The patient's quality of life was subjectively assessed using the twelve-item quality of life questionnaire. ${ }^{16}$ This is a well established, standardized, generic measure of perceived health-related quality of life. It also contains four subscales which deal with activities of daily living as follows: self care (includes bathing, eating, dressing and defaecating), mobility (includes walking to a neighbour's house, farm, market and doing household chores), social interaction (includes attending functions and meeting friends), and mental wellbeing (does patient feel dejected or feel he/she is a burden to others?). Patients were asked if they had any difficulty in performing the mentioned task (even with their glasses where applicable) and answers were scored. The scores were based on all applicable items and the amount of reported difficulty experienced in performing those activities (table 1).

Table 1. The scoring system for the QOL and VF questionnaire

\begin{tabular}{lcc}
\hline Response & $\begin{array}{c}\text { Numerical } \\
\text { value }\end{array}$ & Score \\
\hline 1. NO & 1 & 100 \\
2. YES & & \\
$\quad \begin{array}{l}\text { If yes, how much difficulty do you } \\
\text { currently have with the activity? }\end{array}$ & 2 & 75 \\
a. A little & 3 & 50 \\
b. A moderate amount & 4 & 25 \\
c. A great deal & 5 & 0 \\
d. 'Unable to do' because of vision &
\end{tabular}

The final score produced by this index ranges from 0 (unable to do all applicable activities) to a maximum of 100 (able to do all applicable items without difficulty). ${ }^{16}$

Preoperatively, uniocular cataract-blind patients who had a VA of $\geq 6 / 18$ in the second eye had mean VF and QOL scores of 83.9 (SD 3.5) and 86.9 (SD 4.2) respectively, while those who had a VA of $<6 / 60-3 / 60$ in the better eye had mean 
VF and QOL scores of 37.9 (SD 5.2) and 46.4 (SD 6.6) respectively (figure 1 ). postoperative period, the mean preoperative VF and QOL scores of the blind patients were subdivided into two Seventy-eight binocularly blind patients who had one eye operated, had mean VF and QOL scores of 15.4 (SD 3.8 ) and 22.5 (SD 4.5) respectively, while 19 binocularly blind

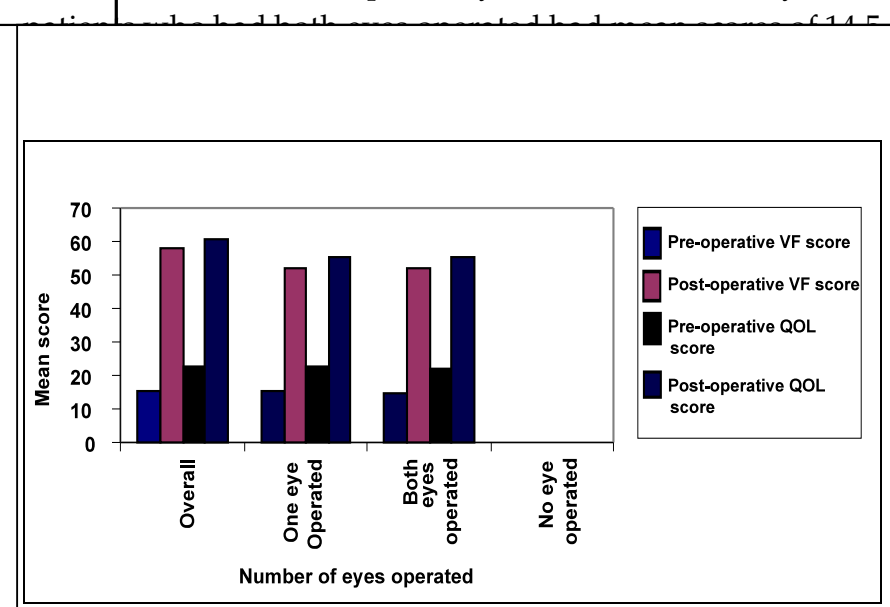

Figure 1. Mean scores of VF and QOL for uniocularly blind patients.

\section{Data Analysis}

Visual outcome was defined using the WHO classification. Association between vision status and VF/QOL scores were assessed by Pearson's correlation coefficient.

\section{RESULTS}

Two hundred patients were recruited; one hundred and nineteen $(59.5 \%)$ male and $81(40.5 \%)$ female participants with a male to female ratio of 1.5:1. Their ages ranged from $42-86$ years (mean of 61.08 years, SD of 9.4 ). About $34.5 \%$ of the study population were farmers. Ninety-seven $(48.5 \%)$ patients were blind and $67(33.5 \%)$ were uniocularly blind preoperatively. In all, 183 eyes (83.6\%) were blind preoperatively (table 2 ).

Table 2. Distribution of patients' preoperative visual acuity

\begin{tabular}{lcccc}
\hline Category of vision & \multicolumn{2}{c}{$\begin{array}{c}\text { Preoperative } \\
\text { uniocular VA }\end{array}$} & \multicolumn{2}{c}{$\begin{array}{c}\text { Preoperative } \\
\text { binocular VA }\end{array}$} \\
\cline { 2 - 5 } & No & $\%$ & No & $\%$ \\
\cline { 2 - 5 } $6 / 18$ or better & 2 & 0.9 & 30 & 15 \\
$<6 / 18-6 / 60$ & 7 & 3.2 & 41 & 20.5 \\
$<6 / 60-3 / 60$ & 27 & 12.3 & 32 & 16 \\
$<3 / 60$ PL & 183 & 83.6 & 97 & 48.5 \\
\hline Total & 219 & 100 & 200 & 100 \\
\hline
\end{tabular}

The mean VF and QOL scores of the 97 blind patients were 15.2 (SD 3.9) and 22.4 (SD 4.5) respectively (figure 2). However, for the purpose of comparison in the
There was a positive correlation between patient's preoperative objective visual function (VA) and subjective visual function, correlation coefficient ( $r$ ) was 0.92 . Similarly, a positive correlation was observed between preoperative VA and QOL, correlation coefficient ( $\mathrm{r}$ ) was 0.83 . One hundred and fifty-one patients were seen six weeks after surgery and $10.5 \%$ of the eyes had a satisfactory physiological outcome on the first postoperative day, while , 53.4\% and $73.6 \%$ had a satisfactory outcome on the sixth postoperative week with available correction and best correction respectively. Also $42.9 \%, 11.2 \%$ and $8.8 \%$ of eyes had poor outcome at the same period respectively. Table 3 compares the World Health Organization (WHO) recommended visual outcome at various periods with actual attainments in the study population.

Six weeks after surgery, patients who were uniocularly cataract blind before surgery had recorded some increase in their mean VF and QOL scores. There was an increase in mean scores in VF and QOL scores of 2.5 and 5 respectively for patients who had a preoperative VA of $6 / 18$ or better in the second eye, and an increase of 26.9 and 25.1 respectively for patients who had a preoperative VA of $<6 / 60-3 / 60$ in the better eye. The poorer the preoperative VA in the better eye, the higher the increase in the mean score obtained (figure 1).

The increase in functional outcome was more remarkable in eyes that were binocularly blind preoperatively. There was an increase in mean VF and QOL scores of 36.8 and 32.8 respectively for binocularly-blind patients who had one eye operated and an increase of 58.2 and 51.1 for binocularly cataract-blind patients who had both eyes operated (figure 2). 
Table 3. Physiological outcome at 6 weeks post-operative period in comparison with WHO guidelines

\begin{tabular}{|c|c|c|c|c|}
\hline $\begin{array}{l}\text { Post- } \\
\text { operative } \\
\text { visual } \\
\text { acuity }\end{array}$ & $\begin{array}{c}\text { Available } \\
\text { correction } \\
\text { (recommen- } \\
\text { ded by } \\
\text { WHO) } \\
\%\end{array}$ & $\begin{array}{c}\text { Best } \\
\text { correction } \\
\text { (recommen- } \\
\text { ded by } \\
\text { WHO } \\
\%\end{array}$ & $\begin{array}{c}\text { Available } \\
\text { Correction } \\
\text { (161 eyes) }\end{array}$ & $\begin{array}{c}\text { Best } \\
\text { Correction } \\
\text { (125 eyes) }\end{array}$ \\
\hline $\begin{array}{l}\text { Good } \\
\text { outcome } \\
\text { (6/18 or } \\
\text { better) }\end{array}$ & $>80$ & $>90$ & $86 \quad(53.4)$ & 92 (73.6) \\
\hline $\begin{array}{l}\text { Borderline } \\
\text { outcome } \\
(<6 / 18- \\
6 / 60)\end{array}$ & $<15$ & $<5$ & $(35.4)$ & $(17.6)$ \\
\hline $\begin{array}{l}\text { Poor } \\
\text { Outcome } \\
(<6 / 60)\end{array}$ & $<5$ & $<5$ & $18 \quad(11.2)$ & $(8.8)$ \\
\hline Total & 100 & 100 & $161 \quad(100)$ & $125(100)$ \\
\hline
\end{tabular}

Overall, the mean VF and QOL scores for patients who were binocularly blind were 58.3 and 60.5 respectively. The mean VF and QOL scores for blind patients who had 1 eye operated were 52.2 and 55.3 respectively, and for patients who had both eyes operated, the scores were 72.7 and 73.2 respectively. Ninety-four (62.2\%) patients were satisfied with the outcome of surgery and $27(17.9 \%)$ rated it as good. Twenty-eight $(18.5 \%)$ patients were satisfied with the hospital environment, $37(24.5 \%)$ were satisfied with the conduct of hospital staff and $25(16.6 \%)$ rated the surgical process as relatively pain free (table 4 ).

Table 4. Extent of patients' satisfaction with the hospital environment, friendliness of hospital staff, surgery and visual restoration

\begin{tabular}{lcccc}
\hline \multicolumn{3}{c}{ Parameters } & & \\
\hline $\begin{array}{l}\text { Level of } \\
\text { Satisfaction }\end{array}$ & Environment & Friendliness & Surg. & $\begin{array}{c}\text { Visual } \\
\text { Restoration }\end{array}$ \\
& No $(\%)$ & No $(\%)$ & No $(\%)$ & No $(\%)$ \\
\hline $\begin{array}{l}\text { Very good } \\
\text { Good }\end{array}$ & $28(18.5)$ & $37(24.5)$ & $25(16.6)$ & $94(62.2)$ \\
Fair & $46(30.5)$ & $45(29.8)$ & $45(29.8)$ & $13(8.6)$ \\
Not & $1(0.7)$ & $3(2)$ & $4(2.6)$ & $17(11.3)$ \\
\hline satisfactory & $151(100)$ & $151(100)$ & $151(100)$ & $151(100)$ \\
\hline \begin{tabular}{l} 
Total \\
\hline
\end{tabular} & & & & \\
\hline
\end{tabular}

\section{DISCUSSION}

The VF/QOL questionnaires used in this study were originally developed for a large-scale clinical trial of cataract surgery in India. ${ }^{17}$ Both questionnaires have been successfully used in surveys of blindness in $\mathrm{Nepal}^{2}$, Shunyi ${ }^{18}$ and Doumen districts of China. ${ }^{19}$

The study design was observational and prospective on a multicentre basis.

Farming was the patients' major occupation. This is not surprising since farming remains a major occupation in the country (especially among rural dwellers). One hundred and eighty-three eyes $(83.6 \%)$ were blind preoperatively. This finding is similar to those of Nwosu et al., ${ }^{20}$ Mahmoud et al., ${ }^{21}$ and Yorton. ${ }^{22}$ Perhaps since most of our patients are farmers, they tend to cope with their work until visual disability has advanced.

Increasing severity of visual impairment was associated with a higher likelihood of reporting problems with mobility, self-care and usual activities. This is similar to what was observed by Rosen et al., ${ }^{23}$ Wang et al., ${ }^{24}$ and Mingguang et al., ${ }^{19}$ and highlights the impact of visual impairment on the wider well-being of an individual. Postoperatively, patients reported significant improvements in QOL and VF scores. The scores for binocularly blind patients and patients with normal or near normal vision were similar to those observed in Nepal. ${ }^{2,3}$ The increase in mean VF and QOL scores was more remarkable in patients who were binocularly blind preoperatively $(\mathrm{p}<0.05)$. This is similar to what was observed by Owsley et al. $^{25}$ The level of the postoperative VA in the operated eye seems to be the most significant factor for good functional outcome and satisfaction after surgery. The cataract-blind patient thus benefited the most from cataract surgery, and most of them should be able to live a relatively independent life after surgery.

The fact that absence of co-existing ocular morbidity was an exclusion criterion may have contributed to the observed improvement in VF/QOL as was also observed by Mozaffarieh et al. ${ }^{26}$

Observer bias might have also influenced the strength of the correlation between VA and VF/QOL, since interviewers were not masked as to the general vision status of the patients they were interviewing.

This study revealed that $88.8 \%$ of patients had a VA of $6 / 60$ or better with available correction six weeks after surgery. This offers good functional vision for our patients who are mostly farmers, traders and housewives. It is possible that most of those (up to $25 \%$ of the study population) who defaulted on their appointments did so because they were satisfied with their vision and did not see any reason to travel long distances to attend an often overcrowded clinic.

Up to $80 \%$ of patients indicated satisfaction with the visual outcome. This is in agreement with what was observed 
by Maaji in Gombe $^{27}$ and Njikamp et al. ${ }^{28}$ The better psychological outcome observed may be attributed to the fact that majority of the patients in the study population could do well with a VA of $6 / 60$ as this may be adequate for their ADL. Secondly, cataract blind patients are more likely to be psychologically satisfied with a VA of $6 / 60$ or better since this makes a whole lot of difference in their daily activities. Another reason for the observed higher proportion of persons who expressed satisfaction with visual restoration may be due to the general attitude of respondents who may be reluctant to offer a negative response because the culture upholds politeness, and patients may be afraid that a negative response may offend the interviewer.

Seventeen patients $(11.3 \%)$ rated the visual outcome as unsatisfactory. Majority of these were patients with uniocular cataract who had good vision in the other eye preoperatively and were yet to appreciate the outcome of surgery since the best correction was yet to be prescribed. It was, however, disturbing to have $11.3 \%$ of patients dissatisfied. While satisfied cataract patients could serve as excellent motivators for others to have surgery, patients who are dissatisfied could have the opposite effect, and fear of a poor outcome may be a legitimate reason for patients to refuse cataract surgery. ${ }^{29}$ Monitoring of cataract outcomes would therefore be useful to ensure continuous improvement in quality.

Cataract is one of the priority diseases of the global initiative VISION 2020: "The Right to Sight" on the basis of its contribution to the burden of blindness. Interventions that are aimed at improving the quality of life of those who are blind or those who are visually impaired could be more successful if they focus on improving the quality of cataract surgery and the number of surgeries. Long-term follow up and postoperative optical correction are essential to achieving good visual outcome.

Providing cataract services at an affordable cost to the populace at large is an important way of reducing visual impairment from cataract and improving quality of life. Barriers to eye care should be taken into account while planning the appropriate interventions.

\section{CONCLUSION}

Visual impairment from cataract has a wide implication for health and the quality of life of patients. Our findings further echo the evidence of disability associated with cataract visual impairment among people on the African continent. Cataract surgery in our environment leads to a dramatic increase in the quality of life of many patients.

\section{REFERENCES}

1. Resnikoff S, Pascolini D, Etya'ale D, Kocur I, Pararajasegaram
R, Pokharel GP, Mariotti SP. Global data on visual impairment in $t$ the year 2002. Bull. WHO 2004; 82: 844-851.

2. Pokharel GP, Selvaraj S, Ellwein LB. Visual functioning and quality of life outcome between cataract operated and unoperated blind populations in Nepal. Br J Ophthalmol 1998; 82: 60-65.

3. Nutheti R, Keeffe JE, Shamanna BR, Nirmalan PK, Krishnaiah $\mathrm{S}$, Thomas R. Relationship between visual impairment and eye diseases and visual function in Andhra Pradesh. Ophthalmology 2007; 114(8): 1552-7.

4. Polack S, Kuper H, Mathenge W, Fletcher A, Foster A. Cataract visual impairment and quality of life in a Kenyan population. Br J Ophthalmol 2007; 91(7): 927-32.

5. Nutheti R, Shamana BR, Nirmalan PK, Keeffe JE, Krishnaiah S, Rao GN, Thomas R. Invest Ophthalmol Vis Sci 2006; 47(11): 47428.

6. Nirmalan PK, Tielsch JM, Katz J, Thulasiraj RD, Krishnadas R, Ramakrishnan R, Robin AL. Relationship between vision impairment and eye disease to vision-specific quality of life and function in rural India: The Aravind comprehensive eye survey. Invest Ophthalmol Vis Sci 2005; 46(7): 2308-12.

7. Knudtson MD, Klein BE, Klein R, Cruickshanks KJ, Lee KE. Age-related eye diseases, quality of life and functional activity. Arch Ophthalmol 2005; 123(6): 807-14.

8. Pararajasegaram R. Importance of monitoring cataract surgical outcomes. J Comm Eye Health 2002; 15(44): 49-50.

9. Dandona L, Limburg $\mathrm{H}$. What do we mean by cataract outcomes? J. Comm. Eye Health 2000; 13(35): 35-36.

10. Apple DJ, Ram J, Foster A, Peng Q. Cataract epidemiology and service delivery. Elimination of cataract blindness: A global perspective. Special Supplement. Surv Ophthalmol 2000; 45(1): 32-44.

11. Cassard SD, Patrick DL, Damiano AM. Reproducibility and responsiveness of the VF-14. An index of functional impairment in patients with cataract. Arch Ophthalmol 1995; 113: 1508-13.

12. Wolffsohn JS, Cochrane Al, Watt NA. Implementation methods for vision related Quality of Life questionnaires. Br JOphthalmol 2000; 84(9): 1035-40.

13. Chang MA, Congdon NG, Baker SK, Bloem MW, Savage H, Sommer A. The surgical management of cataract: barriers, best practices and outcomes. Int Ophthalmol 2007 [Epub ahead of print].

14. West SK, Valmadrid CT. Epidemiology of risk factors for age related cataract. Surv Ophthalmol 1995; 39(4): 323-33.

15. Limburg H. Monitoring Cataract surgical outcomes: Methods and tools. J Comm Eye Health 2002; 15(44): 51-53.

16. Desai P, Reidy A, Minassian DC, Vafidis G, Bolger J. Gains from cataract surgery: Visual function and quality of life. $\mathrm{Br} J$ Ophthalmol 1996; 80: 868-873.

17. Fletcher A, Vijaykumar V, Selvaraj S et al. The Madurai Intraocular Lens study III: Visual Functioning and quality of life outcomes. Am J Ophthalmol 1998; 125: 26-35.

18. Zhao J, Sui R, Jia L, et al. Visual acuity and quality of life outcomes in patients with cataract in Shunyi County, China. Am J Ophthalmol 1998; 126: 515-23.

19. Mingguang He, Jingjing $\mathrm{Xu}$, Shaozhen Li, Kaili $\mathrm{Wu}$, Sergio $\mathrm{R}$ 
Munoz, Leon B Ellwein. Visual acuity and quality of life in patients with cataract in Doumen County, China. Ophthalmology 1999; 1609-1615.

20. Nwosu SNN, Onyekwe LO. Intraocular lens implantation surgery in Onitsha, Nigeria. Nig J Ophthalmol 2002; 1(1): 5-9.

21. Mahmoud BA, Kyari F, Achi IB, Ozomela CP, Abiose A. Audit of outcome of an extracapsular cataract extraction and posterior chamber intraocular lens training course. $\mathrm{Br} J$ Ophthalmol 2002; 84: 848-51.

22. Yorton D, Foster A. Audit of extracapsular cataract extraction and posterior chamber lens implantation as a routine treatment for age-related cataract in East Africa. $\mathrm{Br} J$ Ophthalmol 1999; 83: 897-901.

23. Rosen PN, Kaplan RM, David K. Measuring outcome of cataract surgery using the quality of well-being scale and VF14 Visual Function Index. J Cataract Refract Surg 2005; 31(2): 369-78.

24. Wang JJ. Mitchell P, Smith W. Vision and low self-rated health: The Blue Mountain Eye Study. Invest Ophthalmol Vis Sci 2000; 41: 49-54.
25. Owsley C, McGwin G Jr, Scilley K, Meek GC, Seker D, Dyer A. Impact of cataract surgery on health-related quality of life in nursing home residents. Br J Ophthalmol 2007; 91(10): 135963

26. Mozaffarieh M, Krepler K, Heinzl H, Sacu S, Wedrich A. Visual function, quality of life and patient satisfaction after ophthalmic surgery: A comparative study. Ophthalmologica 2004; 218(1): 26-30.

27. Maaji AT. Assessment of cataract surgery and its outcome in Gombe State. FMCOphth dissertation. Lagos, National Postgraduate Medical College of Nigeria.2001:30-57.

28. Njikamp MD, Nuijts RM, Borne B, Weber CA, Van der Horst F, Hendrikse F. Determinants of patient satisfaction after cataract surgery in 3 settings. J Cataract Refract Surg 2000; 26(9): 1379-88. 